NASA/TM-2004-212955

Quantitative Rainbow Schlieren Deflectometry as a Temperature Diagnostic for Spherical Flames

Douglas A. Feikema

Glenn Research Center, Cleveland, Ohio 
Since its founding, NASA has been dedicated to the advancement of aeronautics and space science. The NASA Scientific and Technical Information (STI) Program Office plays a key part in helping NASA maintain this important role.

The NASA STI Program Office is operated by Langley Research Center, the Lead Center for NASA's scientific and technical information. The NASA STI Program Office provides access to the NASA STI Database, the largest collection of aeronautical and space science STI in the world. The Program Office is also NASA's institutional mechanism for disseminating the results of its research and development activities. These results are published by NASA in the NASA STI Report Series, which includes the following report types:

- $\quad$ TECHNICAL PUBLICATION. Reports of completed research or a major significant phase of research that present the results of NASA programs and include extensive data or theoretical analysis. Includes compilations of significant scientific and technical data and information deemed to be of continuing reference value. NASA's counterpart of peerreviewed formal professional papers but has less stringent limitations on manuscript length and extent of graphic presentations.

- TECHNICAL MEMORANDUM. Scientific and technical findings that are preliminary or of specialized interest, e.g., quick release reports, working papers, and bibliographies that contain minimal annotation. Does not contain extensive analysis.

- CONTRACTOR REPORT. Scientific and technical findings by NASA-sponsored contractors and grantees.
- CONFERENCE PUBLICATION. Collected papers from scientific and technical conferences, symposia, seminars, or other meetings sponsored or cosponsored by NASA.

- SPECIAL PUBLICATION. Scientific, technical, or historical information from NASA programs, projects, and missions, often concerned with subjects having substantial public interest.

- TECHNICAL TRANSLATION. Englishlanguage translations of foreign scientific and technical material pertinent to NASA's mission.

Specialized services that complement the STI Program Office's diverse offerings include creating custom thesauri, building customized databases, organizing and publishing research results ... even providing videos.

For more information about the NASA STI Program Office, see the following:

- Access the NASA STI Program Home Page at http://www.sti.nasa.gov

- E-mail your question via the Internet to help@sti.nasa.gov

- Fax your question to the NASA Access Help Desk at 301-621-0134

- Telephone the NASA Access Help Desk at 301-621-0390

- Write to:

NASA Access Help Desk

NASA Center for AeroSpace Information 7121 Standard Drive

Hanover, MD 21076 
NASA/TM-2004-212955

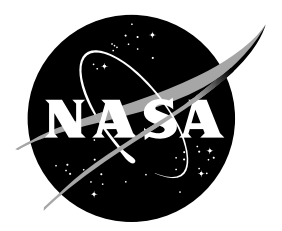

\section{Quantitative Rainbow Schlieren Deflectometry as a Temperature Diagnostic for Spherical Flames}

Douglas A. Feikema

Glenn Research Center, Cleveland, Ohio

Prepared for the

42nd Aerospace Sciences Meeting and Exhibit

sponsored by the American Institute of Aeronautics and Astronautics

Reno, Nevada, January 5-8, 2004

National Aeronautics and

Space Administration

Glenn Research Center 


\section{Acknowledgments}

This work was supported by the NASA Microgravity Combustion Program. The author acknowledges Professor S.D. Tse, Rutgers University, and Professor C.K. Law, Princeton University, for providing the one-dimensional, time dependant Chemkin calculations shown in figures 4 to 6 . The author also acknowledges helpful discussions with Dr. Paul Greenberg and Dr. Kurt Sacksteder, the Technical Monitor for this NASA grant, both from NASA Glenn Research Center. Also acknowledged is Dr. Fletcher Miller of the National Center for Microgravity Research for his assistance with generating the rainbow color filters as shown in figure 2. Dr. Rita Cognion and associates of ZIN Technologies are also gratefully acknowledged for setting up hardware and conducting KC-135 and normal gravity experiments. Ms. Tequila Harris, a summer intern, is acknowledged for her assistance in performing detailed data analysis culminating in figure 7.

Available from

NASA Center for Aerospace Information 7121 Standard Drive

Hanover, MD 21076
National Technical Information Service 5285 Port Royal Road Springfield, VA 22100 


\title{
Quantitative Rainbow Schlieren Deflectometry as a Temperature Diagnostic for Spherical Flames
}

\author{
Douglas A. Feikema \\ National Aeronautics and Space Administration \\ Glenn Research Center \\ Cleveland, Ohio 44135
}

\section{Summary}

Numerical analysis and experimental results are presented to define a method for quantitatively measuring the temperature distribution of a spherical diffusion flame using Rainbow Schlieren Deflectometry in microgravity. First, a numerical analysis is completed to show the method can suitably determine temperature in the presence of spatially varying species composition. Also, a numerical forward-backward inversion calculation is presented to illustrate the types of calculations and deflections to be encountered. Lastly, a normal gravity demonstration of temperature measurement in an axisymmetric laminar, diffusion flame using Rainbow Schlieren deflectometry is presented. The method employed in this paper illustrates the necessary steps for the preliminary design of a Schlieren system. The largest deflections for the normal gravity flame considered in this paper are $7.4 \times 10^{-4}$ radians which can be accurately measured with $2 \mathrm{~m}$ focal length collimating and decollimating optics. The experimental uncertainty of deflection is less than $5 \times 10^{-5}$ radians.

\section{Introduction}

Optical diagnostic techniques can be classified as either local or path integrated. Local measurement techniques for microgravity combustion research include (1) Laser Doppler Velocimetry (LDV) and Particle Image Velocimetry (PIV) to measure the velocity field, and (2) Rayleigh scattering and Laser-Induced Fluorescence (LIF) or Planar Laser-Induced Fluorescence (PLIF) to measure temperature and/or species concentrations (ref. 1). Application of these techniques presents unique challenges and difficulties in the microgravity environment where mass, volume, and electrical power available are highly limited and severely constrained. In addition, remote operation is also often required further complicating the implementation. The LDV method enables detailed velocity information at a point but in order to determine the entire velocity field Particle Image Velocimetry (PIV) (ref. 2) is often applied. However, PIV methods are typically not well suited to characterize extreme turbulence because of low spatial and temporal resolution and cannot account for large out of plane motions. Seeding of the flow is a challenge in microgravity as well. The scattering and fluorescence methods require bulky, power consuming lasers often unsuitable for use in microgravity, and are sensitive to misalignment. These methods will become more applicable to microgravity as technology advances in solid-state lasers and advanced imaging systems.

The path-integrated techniques used for microgravity overcome some of the drawbacks of the local measurements techniques. The measurements must be inverted tomographically to obtain local distributions of scalar or flow properties of interest. The inversion process is relatively simple for laminar flows if symmetry can be assumed. But for turbulent flows the deconvolution is tedious. Examples of path-integrated methods applied in microgravity include emission/ absorption imaging pyrometry (ref. 1), for measurement of temperature, $\mathrm{CH}$ emission tomography (refs. 3 and 4), infrared diode laser wavelength modulation spectroscopy (WMS) for measurement of oxygen and water vapor concentrations (refs. 5 to 8), shearing plate interferometry (ref. 9), FanBeam Emission Tomography (FBET) (ref. 10), 
and quantitative rainbow Schlieren deflectometry (ref. 11). The objective of this paper is to discuss the application of quantitative rainbow Schlieren deflectometry for the case of a laminar spherical flame.

\section{Experiment Description}

The Schlieren method is one of the simplest and oldest methods for visualizing refractive-index inhomogeneities in transparent media with its origins dating back to the 17th century. The Schlieren instrument is sensitive to transverse refractive-index gradients in a media. The present application is a laminar flame. The gradients cause angular deflections of the incoming light rays which are transformed at the filter plane of the Schlieren system by a spatial filter. Many different types of spatial filters have been developed to relate the angular deflections to different quantities. The various types of spatial filters, Schlieren optical configurations and applications are extensively reported in the literature (refs. 12 to 15).

A simple Lens-Type Schlieren System is shown in figure 1. An input lens collimates the light from a light source through a transparent media with transverse gradients of index of refraction, referred to as the test section. The spherical flame is located in the test section. As the light exits the test section, it is angularly deflected according to a line integral eq. (1). The optical inhomogenities refract or bend light rays in proportion to their gradients of refractive index.

$$
\theta_{\text {exit }} \cong \tan \theta_{\text {exit }}=\oint_{L} \nabla n \partial \ell
$$

A decollimating lens refocuses the light onto a filter plane. A continuous rainbow filter shown in figure 2, first introduced by Howes (ref. 16) alleviates undesirable optical discontinuities, and avoids the nonlinear sensitivity associated with conventional grey-scale methods. An image of the test section and the rainbow filter is then focused by a camera lens onto the color sensitive detector, allowing accurate quantification for the color attributes of the resulting image, and hence, the associated ray deflections (ref. 11). The "color" of the resulting Schlieren image is quantified using an RGB relationship as measured using the image

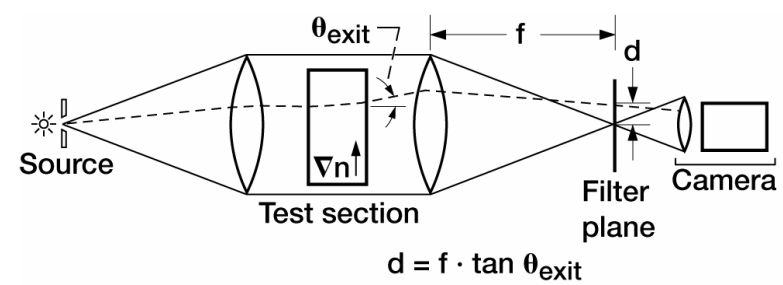

Figure 1.-Schematic drawing of a simple lens-type Schlieren system.

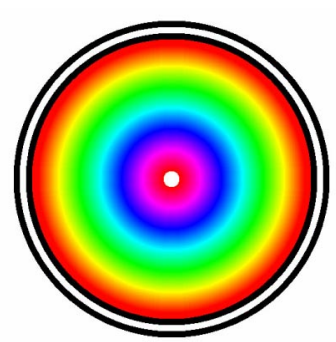

Figure 2.-Typical circular Schlieren rainbow color filter used in microgravity experiments for spherical flames; filter diameter is $\mathbf{8 ~ m m}$ and "clear" center diameter is $0.5 \mathrm{~mm}$.

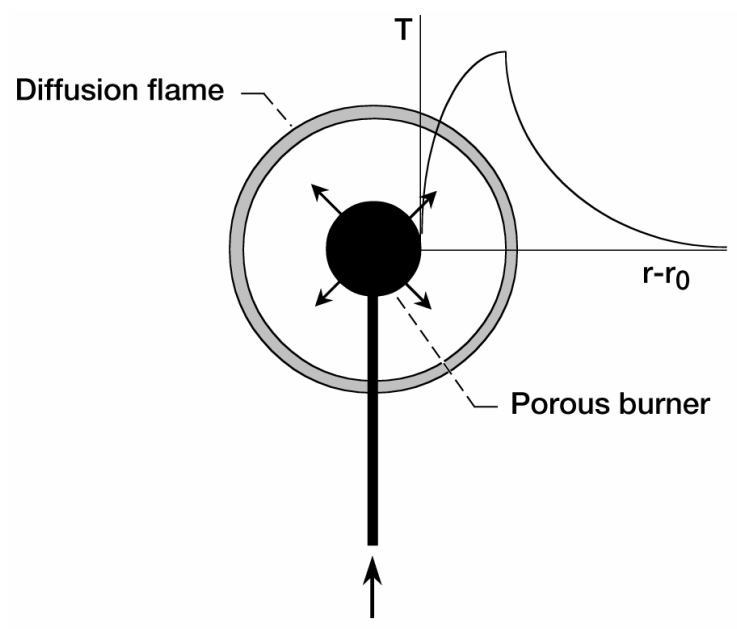

Fuel (oxidizer)

Figure 3.-Schematic representation of the spherical burner generated gaseous diffusion flame experiment.

hue (ref. 11). The spherical burner arrangement is schematically represented in figure 3. Typically, a porous sphere is attached to a "fuel" supply tube and fuel is uniformly dispersed in the vicinity of the burner. A quiescent ambient "air" or other oxidizer diffuses to the reaction zone of the diffusion flame. In microgravity the buoyant effects are significantly eliminated thereby allowing a spherically symmetric, one-dimensional formulation. 


\section{Numerical Analysis to Demonstrate Temperature Sensitivity}

In order to investigate the optical properties of the flame, both the gas composition and temperature must be known (ref. 17) since both affect the index of refraction. A time-dependant, onedimensional numerical model based on Chemkin was used to determine flame temperature and species concentrations (ref. 18). Figure 4 shows a computed radial temperature profile with this model after $5.4 \mathrm{sec}$ from ignition with a fuel composition of $20 \% \mathrm{H}_{2} / 25 \% \mathrm{CH}_{4} / 55 \% \mathrm{~N}_{2}$ and a fuel flow rate of $24 \mathrm{mg} / \mathrm{s}$. This flame is burning in pure air with 21 percent oxygen and 79 percent nitrogen. The hottest part of the flame, $2000 \mathrm{~K}$, is located at $5 \mathrm{~cm}$ from the center of the spherical flame. The ambient air is constant at $300 \mathrm{~K}$ from 13 to $20 \mathrm{~cm}$ indicating that no temperature gradients are present at this position in the domain. The mole fractions of the major species in the flame are nitrogen, oxygen, methane, and hydrogen, are shown plotted in figure 5 over a $20 \mathrm{~cm}$ radial domain after $5.4 \mathrm{sec}$ from ignition. The fuel, methane and hydrogen, and oxidizer, oxygen, are completely consumed at a radial position of $5 \mathrm{~cm}$. The fuel rich side of the flame occurs over the radial domain of $0<r<5 \mathrm{~cm}$. The oxidizer rich side of the flame occurs when $r>5 \mathrm{~cm}$. At radial locations greater than $13 \mathrm{~cm}$ no gradients in flame "composition" are observed. The radial profiles of other important major species in the flame are shown in figure 6. Water vapor, carbon dioxide, and carbon monoxide are produced in the reaction zone of the diffusion zone of the flame. Carbon monoxide is generated on the fuel rich side of the flame but is consumed in the high temperature reaction zone at radial locations approaching $5 \mathrm{~cm}$. The peak values of water vapor and carbon dioxide gas are produced in the highest temperature regions of the flame near $5 \mathrm{~cm}$ and are observed to diffuse toward both the fuel and oxidizer sides of the diffusion flame.

In the determination of the index of refraction in the flame an analysis in which all of the computed major and minor species included in table I have been considered in the calculation of the index of the refraction profile. This analysis is used to answer the following two important

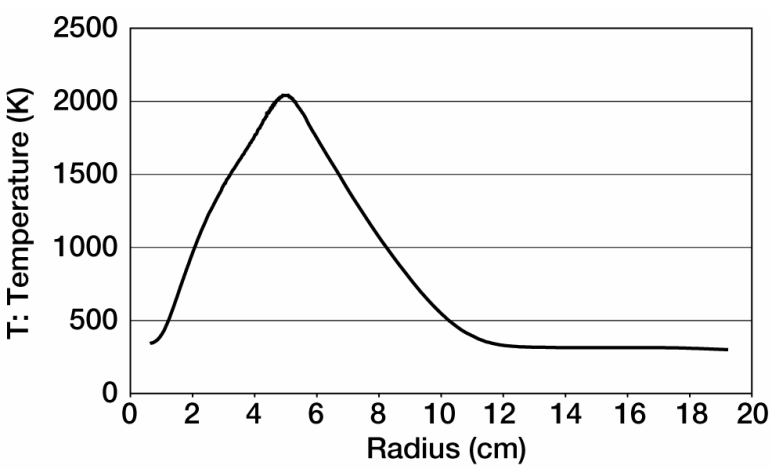

Figure 4.-Computed temperature profile with time dependent Chemkin model for a spherical diffusion flame burning in air at 1.2 atm and $300 \mathrm{~K}$; fuel type: $20 \% \mathrm{H}_{2} / 25 \% \mathrm{CH}_{4} / 55 \% \mathrm{~N}_{2}$ with mass flow rate of $24 \mathrm{mg} / \mathrm{sec}$, time from ignition is $5.4 \mathrm{sec}$.

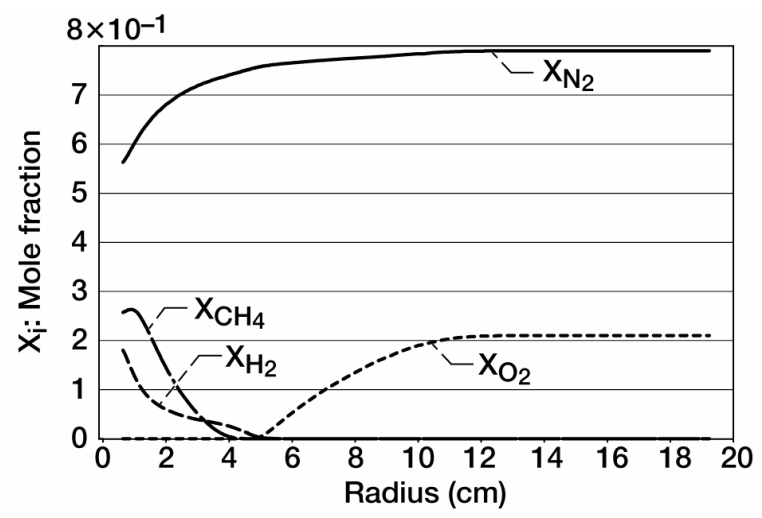

Figure 5.-Fuel and oxidizer specie mole fractions for an adiabatic calculation with fuel $20 \% \mathrm{H}_{2} / 25 \% \mathrm{CH}_{4} /$ $55 \% \mathrm{~N}_{2}$ in air, $1.2 \mathrm{~atm}$, fuel mass flow rate $24 \mathrm{mg} / \mathrm{sec}$, at $5.4 \mathrm{sec}$ after ignition.

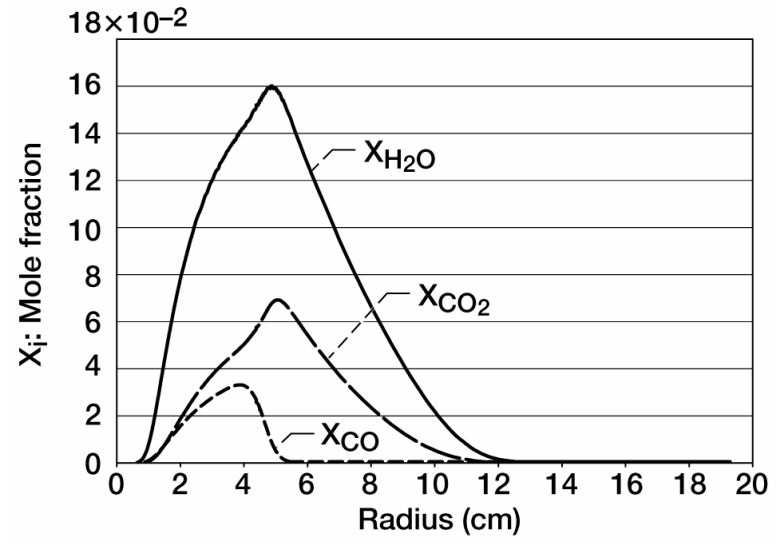

Figure 6.- $\mathrm{H}_{2} \mathrm{O}, \mathrm{CO}_{2}$ and $\mathrm{CO}$ species mole fractions for an adiabatic calculation with fuel $20 \% \mathrm{H}_{2} / 25 \% \mathrm{CH}_{4} /$ $55 \% \mathrm{~N}_{2}$ in air at $1.2 \mathrm{~atm}$, fuel mass flow rate $24 \mathrm{mg} / \mathrm{sec}$, at $5.4 \mathrm{sec}$ after ignition. 
TABLE I.-INDEX OF REFRACTION AT $273.15 \mathrm{~K}$, 1 ATM FOR VARIOUS GASES OF INTEREST (REF. 19).

\begin{tabular}{|l|c|c|}
\hline \multicolumn{3}{|c|}{$\begin{array}{l}\text { Values are relative to a vacuum and for a temperature of } \\
273.15 \mathrm{~K} \text {, wavelength }\end{array}$} \\
\hline \multicolumn{2}{|c|}{$\lambda=590 \mathrm{~nm}$ and $760 \mathrm{~mm}$ pressure } \\
\hline Specie & Formula & $\begin{array}{c}\text { Index of refraction, } \\
\mathrm{n}\end{array}$ \\
\hline Air & $\mathrm{Air}$ & 1.000293 \\
\hline Carbon Dioxide & $\mathrm{CO}_{2}$ & 1.000451 \\
\hline Carbon Monoxide & $\mathrm{CO}$ & 1.000338 \\
\hline Helium & $\mathrm{HE}$ & 1.00036 \\
\hline Hydrogen & $\mathrm{H}_{2}$ & 1.000132 \\
\hline Hydrogen Atom & $\mathrm{H}$ & 1.000407 \\
\hline Methane & $\mathrm{CH}_{4}$ & 1.000444 \\
\hline Methanol & $\mathrm{CH}_{3} \mathrm{OH}$ & 1.000586 \\
\hline Nitrogen & $\mathrm{N}_{2}$ & 1.000297 \\
\hline Oxygen & $\mathrm{O}_{2}$ & 1.000272 \\
\hline Oxygen Atom & $\mathrm{O}$ & 1.000649 \\
\hline Water & $\mathrm{H}_{2} \mathrm{O}$ & 1.000254 \\
\hline
\end{tabular}

questions concerning the sensitivity of Schlieren deflectometry to temperature and gas composition (ref. 17).

(1) How do chemical species affect the index of refraction?

$$
(n(T)-1)_{\text {mix }}=\sum_{i=1}^{N} X_{i} *\left(n_{i}(T)-1\right)_{i}
$$

(2) How does temperature affect the index of refraction?

$$
(n-1)_{h o t}=\left(n_{o}-1\right)_{c o l d} * \frac{T_{o}}{T}
$$

Where $n$ is the index of refraction, $X_{i}$ are the mole fraction of specie $i, N$ is the total number of gas species, $n_{o}$ is the reference index of refraction (ref. 19), listed in table I, $T_{o}$ is the temperature used for the referenced index of refraction, and $T$ is the local gas temperature. Other useful data for the refractivity of combustion gases can be found in ref. 25. Knowing the relative contribution of chemical composition and the temperature on the refractive-index is necessary for quantitative flame measurements.

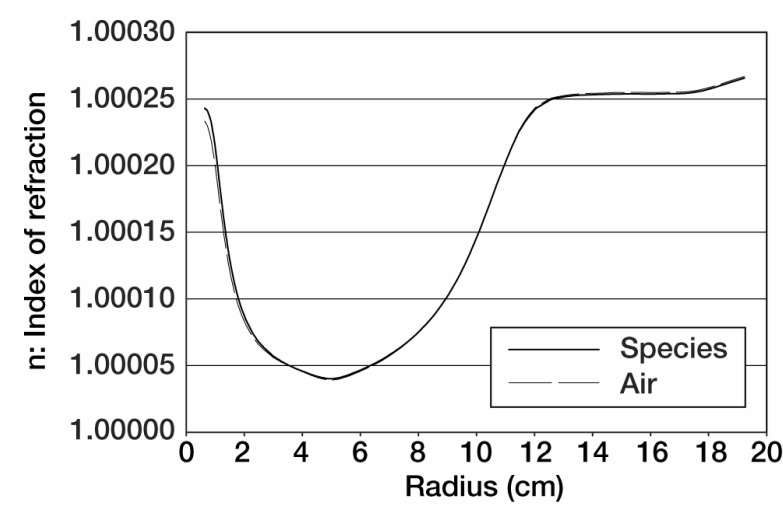

Figure 7.--Index of refraction $n(r)$ profile of the flame with complete species and air as calculated with the Chemkin computed species and temperature profiles, $20 \% \mathrm{H}_{2} / 25 \% \mathrm{CH}_{4} / 55 \% \mathrm{~N}_{2}$ in air at $1.2 \mathrm{~atm}$, fuel mass flow rate $24 \mathrm{mg} / \mathrm{sec}$, at time from ignition of $5.4 \mathrm{sec}$.

Using the data in figures 4 to 6 and eqs. (2) and (3), the refractive index radial profile can be computed.

Figure 7 shows a comparison between the refractive index for air and all of species shown in table I, with the same computed temperature profile. The analysis was conducted on several profiles with similar results represented in figure 7. Figure 7 shows that the index of refraction for the flame is nearly equivalent to high temperature air and therefore the data reduction of refractive-index to temperature can be made to suitable accuracy by neglecting variations in composition. This illustrates the significant effect of temperature rather than gas composition on the variation of index of refraction through the flame. The reasoning for this can be understood by noting the flame is composed of primarily nitrogen, which is also a major component in air. Thus, the gas temperature has the dominant effect on refractive index rather than the gas composition.

\section{Forward-Backward Inversion Calculation on Synthetic Data}

The tomographic reconstruction of an axisymmetric refractive-index distribution from angular deflections (e.g., Schlieren data) for a spherical diffusion flame is demonstrated with a synthetic data set. The purpose of this exercise is 
to show how temperature can be extracted from deflection data as measured from Rainbow Schlieren deflections. In addition, this exercise assists in the design of the Schlieren system by determining both angular and linear deflections. This is conducted for the microgravity spherical diffusion flame described in the previous section and shown schematically in figure 3 .

The angular deflections generated by the spherical diffusion flame can be computed from the radial refractive-index distribution shown in figure 7 using the forward expression (ref. 20).

$$
\varepsilon(y)=2 y \int_{y}^{\infty} \frac{d(n-1)}{d r} \frac{d r}{\left(r^{2}-y^{2}\right)^{1 / 2}}
$$

The corresponding transverse deflections occurring in the plane of the rainbow filter can be computed for a known focal length decollimating lens (ref. 11).

$$
d_{f}(y)=F_{L} \varepsilon(y)
$$

These calculations have been completed in a MATHCAD 2000 program worksheet and the improper integral in eq. (4) has been evaluated with an infinite limit approximation.

Figure 8 shows angular deflection of light rays through the microgravity spherical flame. Over the radial position of $0<r<3 \mathrm{~cm}$ the deflections are negative and the flame acts like a "focusing" lens. For radial stations of $3 \mathrm{~cm}<r<12 \mathrm{~cm}$ the flame disperses the light rays similar to a defocusing lens. The maximum angular deflection is approximately $5.4 \times 10^{-4}$ radians and appears at $9 \mathrm{~cm}$ from the center of the flame. If the ambient conditions in this flame were constant at a radius of $20 \mathrm{~cm}$ the angular deflection should be zero. Examination of figure 8 shows that the angular deflections are in fact nonzero and negative at $20 \mathrm{~cm}$. Physically, however, these deflections should be zero since the flame has constant temperature and gas composition, i.e., pure air, at a radius of $20 \mathrm{~cm}$ as observed in figures 4 to 6 . The reason for this discrepancy is due to curve fitting of the index of refraction profile, figure 7 , which was required in order to make use of the MATHCAD 2000 program. As a result, a

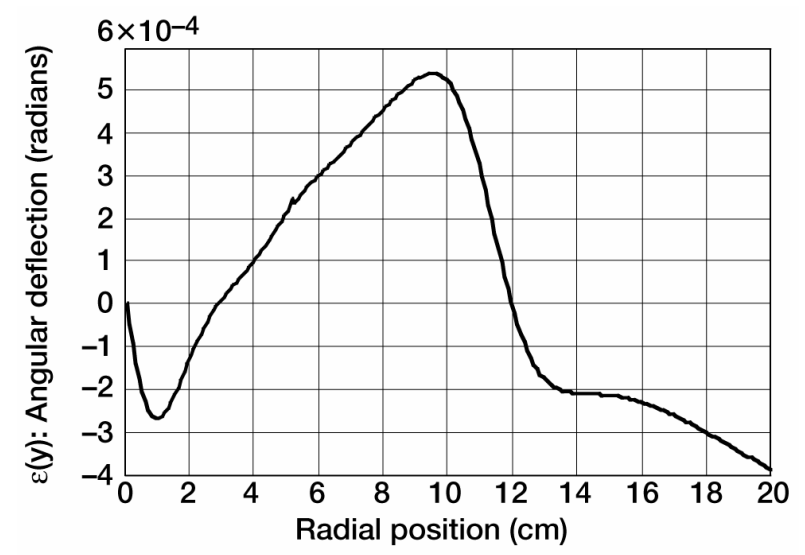

Figure 8.-Angular defection of light rays through the flame shown in figures 4 to 7 as computed using equation (4).

numerical error appears in figure 8 for a radius greater than $15 \mathrm{~cm}$. This curve fitting error, although not physically correct, does not severely impact the final results appearing in figures 10 and 11 . This is actually an interesting result since this demonstrates that experimental uncertainties in measured angular deflections in the ambient gas do not result in large errors of temperature. Also, this shows that the field of view of the Schlieren image need not have constant index of refraction in the ambient condition in order to obtain a quantitative result.

If a decollimating lens of focal length $3 \mathrm{~m}$ is assumed, eq. (5) can be applied to the calculated angular deflections shown in figure 8 to obtain the linear deflections at the filter plane. Figure 9 shows these linear deflections at the filter plane enabling sizing of the color filter. The maximum linear deflection is approximately $1.7 \mathrm{~mm}$ so a rainbow filter of at least $4 \mathrm{~mm}$ in diameter would be required for this application. Since this flame is spherically symmetric an Abel-Transform inversion can be performed to reconstruct the refractive-index field from the deflection information shown in figure 8. The Abel Transform for Refractivity, $\delta(r)=n(r)-1$ (ref. 20), is given as:

$$
\delta(r)=\frac{-1}{\pi} \int_{r}^{\infty} \varepsilon(y) \frac{d y}{\left(y^{2}-r^{2}\right)^{1 / 2}}
$$

where $\quad \delta(r)=n(r)-1$ 


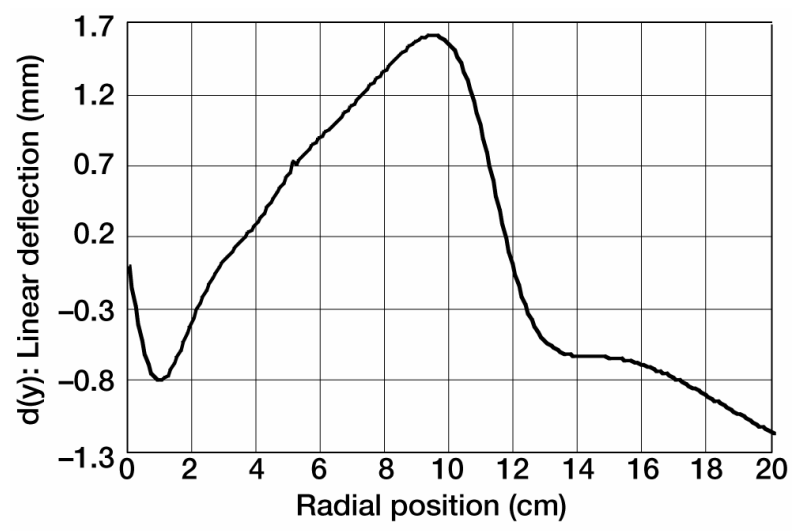

Figure 9.-Linear deflection at the filter plane for the flame shown in figures 4 to 7 as computed using equation (5) for a $3 \mathrm{~m}$ focal length decollimating optic.

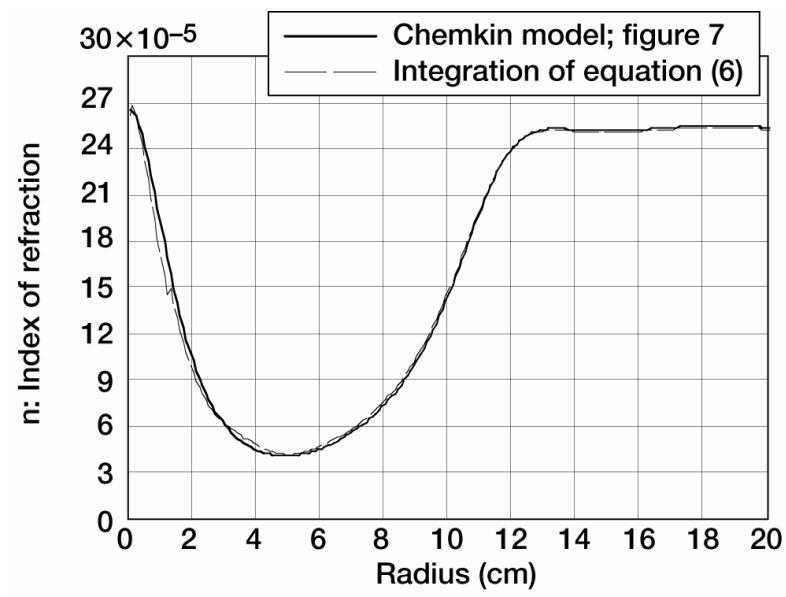

Figure 10.-Comparison of numerically generated index of refraction field based on the Chemkin model with the Abel transformed deflections from figure 7 (eq. (6)) for the flame shown in figures 4 to 7 .

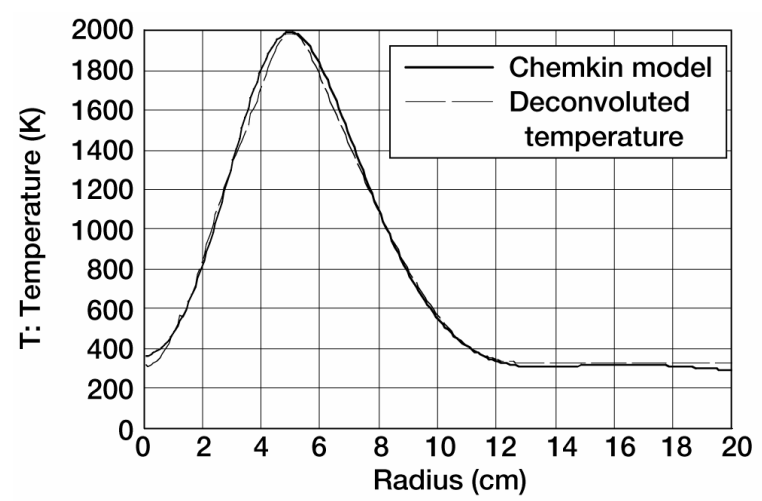

Figure 11.-Comparison of the flame temperature profile with Chemkin model (fig. 4) and Abel transformed angular deflection (fig. 8).
Figure 9 shows the refractive-index field computed using an Abel Transform Inversion calculation using eq. (6) (red line) and the refractive-index calculated from flame properties and shown in figure 7 (blue line). The observed agreement is very good, demonstrating the numerical calculations performed and the deflections computed in figures 8 and 9 are correct. The gas temperature can be rapidly computed from figure 10 using eq. (3) assuming the gas composition is air. As can be seen in figure 11, the Chemkin generated temperature profile in figure 4 (blue line) and the temperature profile derived from the backwardinversion (i.e., Abel Transform) calculation of the synthetic data (red line) produce nearly the same result, demonstrating the methodology.

This exercise also serves to provide a preliminary design for a Rainbow Schlieren system. The maximum angular deflection for a spherical diffusion flame is approximately $5.4 \times 10^{-4}$ radians, such that a decollimating lens having a focal length of $3 \mathrm{~m}$ provides a corresponding maximum lateral deflection in the plane of the rainbow filter of $1.7 \mathrm{~mm}$. Filters of similar dimensions have been previously fabricated. As further verification of this calculation, previous quantitative temperatures have been measured in the 2.2-second drop tower at NASA Glenn Research Center using Rainbow Schlieren deflectometry in flames. In these experiments (refs. 21 and 22) a low Reynolds number, pure hydrogen fuel gas jet was allowed to burn in microgravity. The maximum angular deflections measured were approximately $5 \times 10^{-4}$ radians, in reasonable agreement with the calculation shown in figure 8 .

\section{Demonstration Experiment in Normal Gravity}

A normal gravity demonstration experiment was completed in a steady air coflow flame under atmospheric, normal gravity conditions. The fuel used was $20 \% \mathrm{H}_{2} / 25 \% \mathrm{CH}_{4} / 55 \% \mathrm{~N}_{2}$ at $9.3 \mathrm{ml} / \mathrm{s}$ in a central fuel tube with a surrounding coflowing air at $583 \mathrm{ml} / \mathrm{s}$. The coflow flame is open to the atmosphere and is burning in quiescent, ambient air. The burner specifications have been designed to match the burner used by Santoro et al. (ref. 23). Figure 12 shows the blue flame with a visible flame height of approximately $35 \mathrm{~mm}$ and 


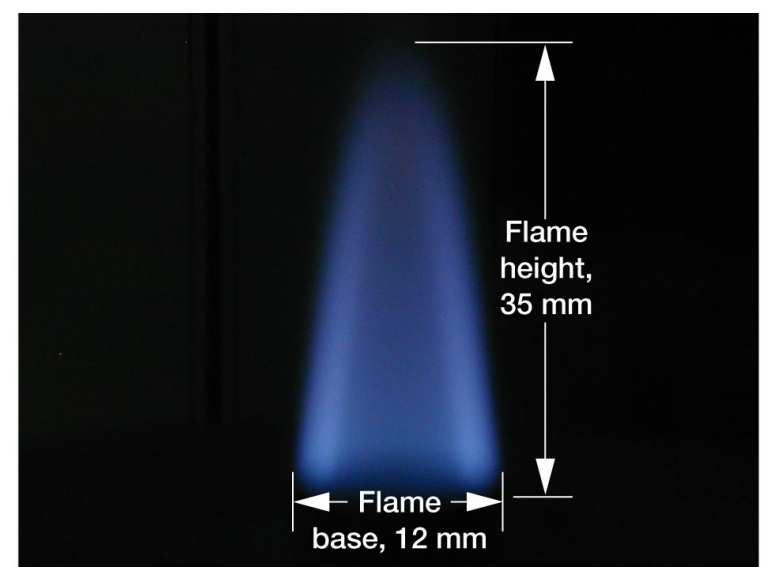

Figure 12.-Visible flame image of "1-g" co-flow flame used for Schlieren demonstration experiment for $20 \% \mathrm{H}_{2} / 25 \% \mathrm{CH}_{4} / 55 \% \mathrm{~N}_{2}$ : fuel flow rate: $9.3 \mathrm{ml} / \mathrm{sec}$ air flow rate: $583 \mathrm{ml} / \mathrm{sec}$.

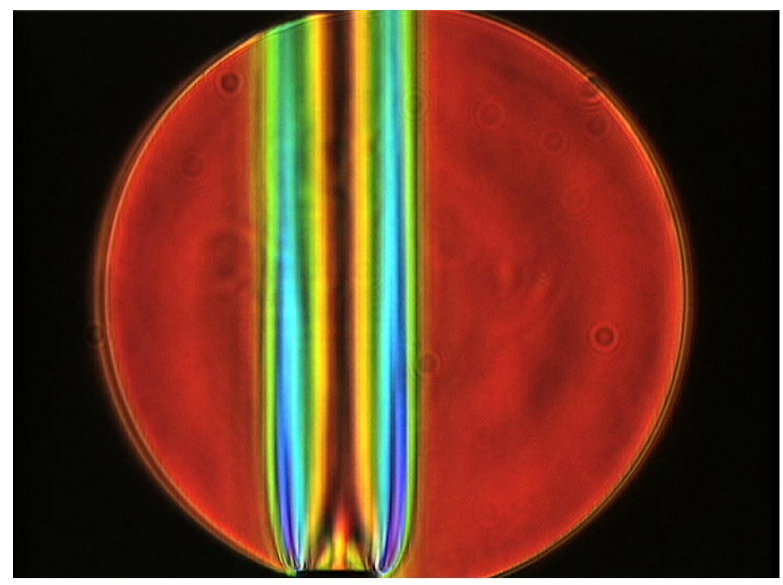

Figure 13.-Color Schlieren image of flame shown in figure 12 with a symmetric color filter.

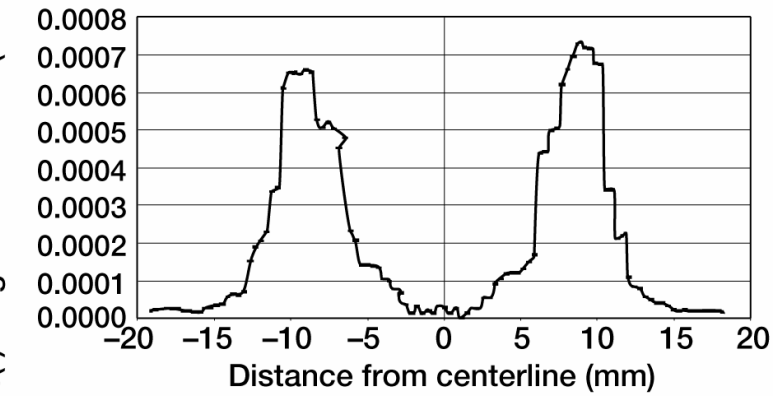

Figure 14.-Measured angular deflections of light rays passing taken directly from figure 13 at $9 \mathrm{~mm}$ above the burner base. flame base of $12 \mathrm{~mm}$. A color Schlieren image was collected with a symmetric filter, shown in figure 13 with a Z-pattern Schlieren system with two off-axis spherical mirrors of focal length $2 \mathrm{~m}$. A symmetric, noncircular rainbow filter of $2 \mathrm{~mm}$ half-width was used to obtain the Schlieren image in figure 13. The "red" background has zero deflection. The measured angular deflection data across the flame at $9 \mathrm{~mm}$ above the flame base is shown in figure 14. The maximum deflection is approximately $7 \times 10^{-4}$ radians, or $1.4 \mathrm{~mm}$ on the filter, at a radial position of $10 \mathrm{~mm}$ from the central axis of the flame. The Schlieren deflection data shows that "perfect" symmetry is not completely achieved but is a reasonable assumption. The experimental or instrument uncertainty is less than $5 \times 10^{-5}$ radians or $0.1 \mathrm{~mm}$ linear deflection, which is very accurate. The angular deflection data shown in figure 14 was then transformed using a simple approximation to the integral shown in eq. (6) (ref. 24).

Figure 15 shows the thermocouple measurements for comparison with the Schlieren at a $9 \mathrm{~mm}$ height above the burner base. The thermocouple measurements have been corrected for radiation losses which are $100 \mathrm{~K}$ at most in the hottest part of the flame located at a radial position of $6 \mathrm{~mm}$. It is noteworthy that the maximum deflection at $r=10 \mathrm{~mm}$ is not equal to the position of maximum flame temperature at $r=6 \mathrm{~mm}$ similar to the numerical calculations presented earlier. This is true since Schlieren deflectometry responds to gradients in the refractive index. A comparison of the thermocouple data and the Schlieren results are presented in figure 16. The results in figure 16 show reasonable agreement with measured thermocouple data and the Schlieren determined temperatures accept near the center of flame. Improvements can be realized in the comparison by improvements in the algorithm to approximate the numerical integration of eq. (6). However, the largest errors will always occur near the center line since the integral in eq. (6) has a mathematical singularity at the radial position of zero. In other words, the solution of eq. (6) for Refractivity blows up as $r$ approaches zero (i.e., as $r \rightarrow 0, \delta \rightarrow \infty$ ) so results at small radii will generally over predict the actual value. 


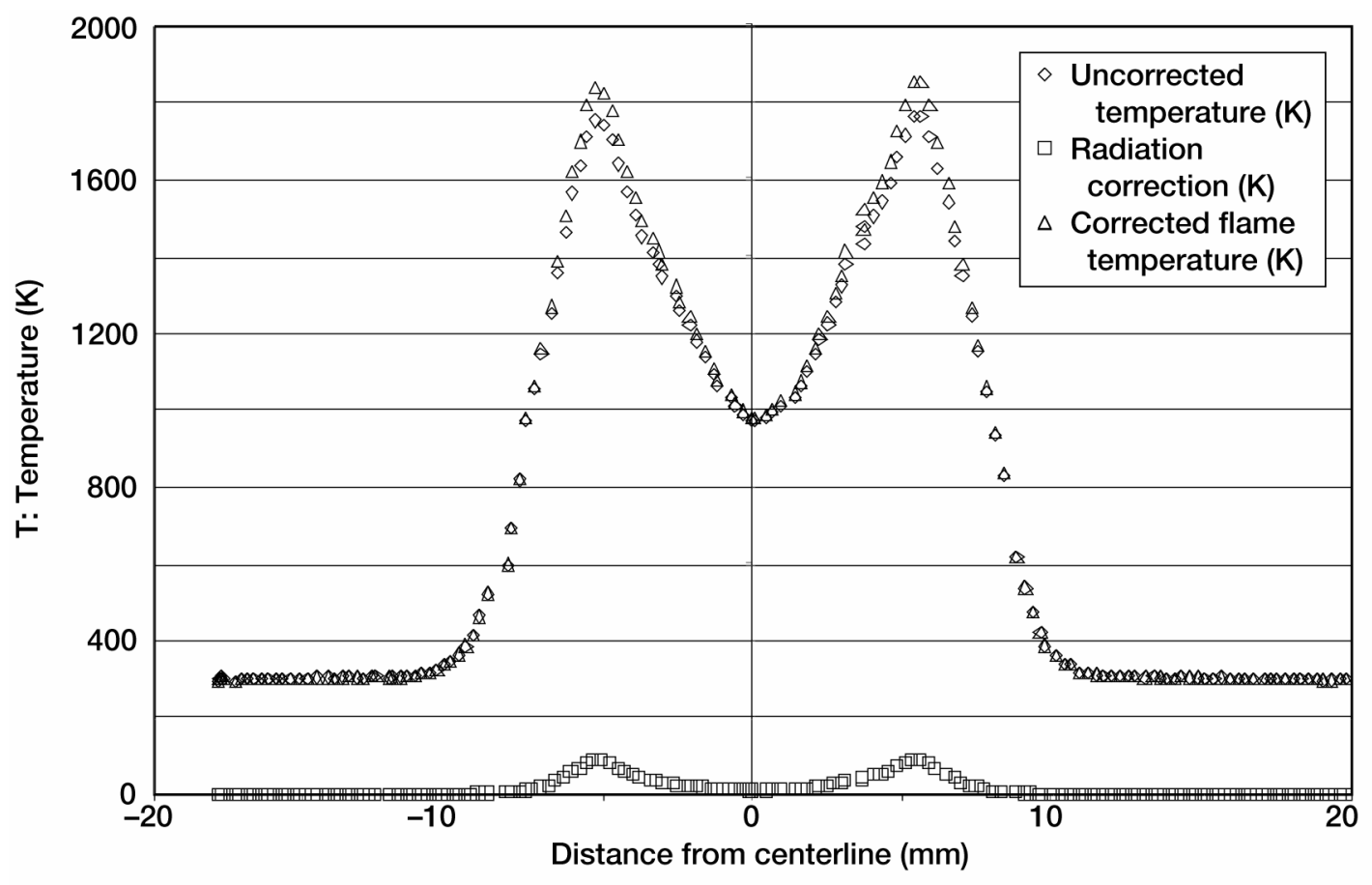

Figure 15.-Radiation corrected flame temperatures measured with thermocouple in flame shown in figure 12 at $9 \mathrm{~mm}$ above burner base.

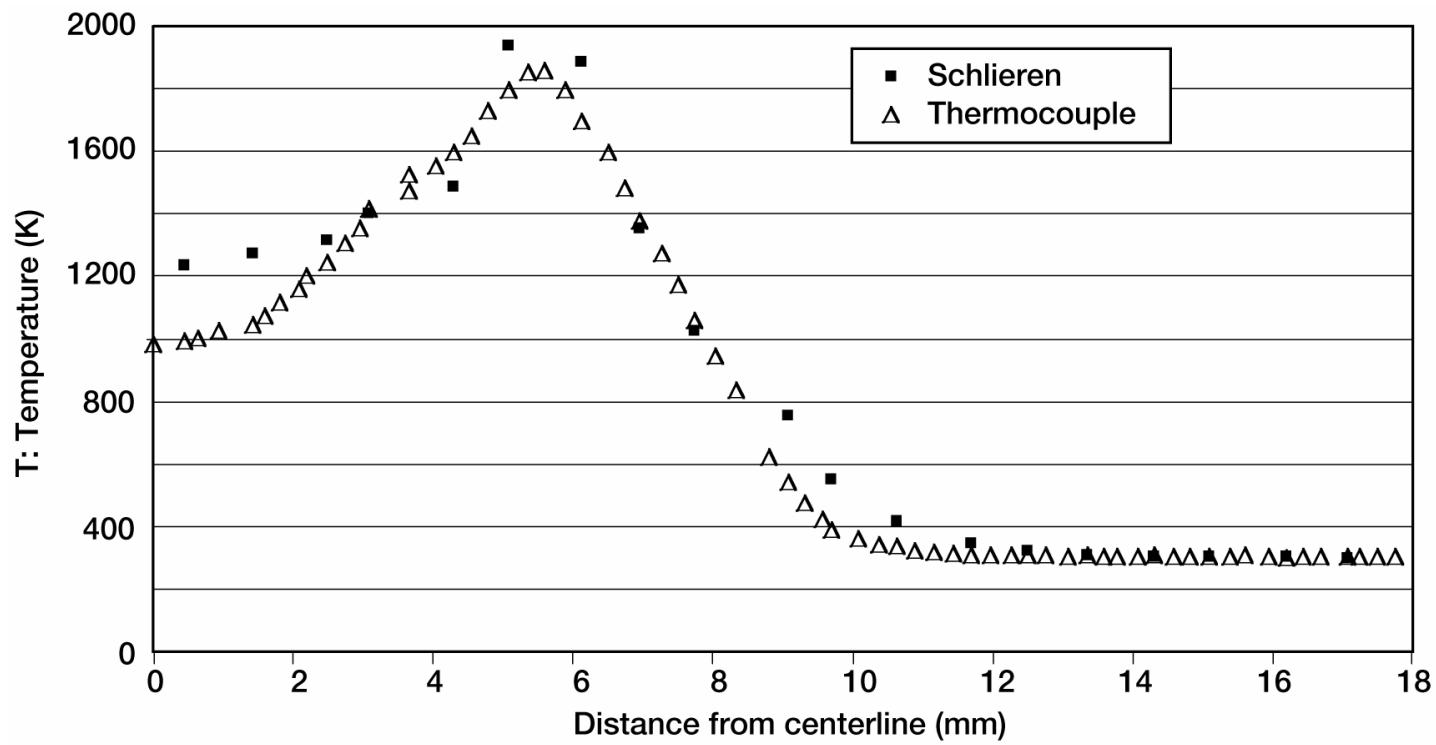

Figure 16.-Temperature comparison between Abel transformed Schlieren data and thermocouple measurements of the flame shown in figure 12 at $9 \mathrm{~mm}$ above the burner. 


\section{Conclusions}

The following conclusions can be made from the results presented.

1. For the case of a fuel blend $20 \% \mathrm{H}_{2} / 25 \%$ $\mathrm{CH}_{4} / 55 \% \mathrm{~N}_{2}$, the gas can be treated analytically equivalent to heated air when performing the Abel transformation since the flame is composed of mostly nitrogen. For other fuels, if the major species concentrations are known, eq. (2) and (3) enable accurate determination of the flame temperature.

2. The methods used in this paper enable a designer to determine the primary parameters for a Schlieren optical system, (a) angular deflections (b) focal lengths of the collimating and decollimating lenses or mirrors, and (c) size of the rainbow filter, based upon flame properties. A numerical model for chemical species and temperature (ref. 18) as well as and forward/backward Abel inversion calculation enables this.

3. A normal gravity demonstration experiment was successfully completed to illustrate the methodology of Quantitative Rainbow Deflectometry for a flame. A comparison of the temperature profile in the flame between a radiation corrected thermocouple and the Abel inverted Schlieren data are in reasonable agreement.

\section{References}

1. Greenburg, P.S., Griffin, D.W., Weiland, K.J., and Yanis, W., "Selected Diagnostics for Microgravity Combustion Science," Proceedings of 4th Microgravity Combustion Workshop, NASA CP-10194, pp. 275-280, 1997.

2. Greenberg, P.S., Wernet, M.P., Yanis, W., Urban, D.L., and Sunderland, P.B., "Development of PIV for Microgravity Diffusion Flames," Proceedings of 7th Microgravity Combustion Workshop, NASA/CP-2003212376, pp. 377-380.
3. Ku, J.C., Greenberg, P.S., "Temperature and Radiative Heat Flux Measurements in Microgravity Diffusion Flames," Proceedings of 4th Microgravity Combustion Workshop, NASA CP-10194, pp. 211-216, 1997.

4. Long, M., Walsh, K., and Smooke, M., "Computational and Experimental Study of Laminar Diffusion Flames in a Microgravity Environment," Proceedings of 4th Microgravity Combustion Workshop, NASA CP-10194, pp. 123-128, 1997.

5. Kane, D.J., Silver, J.A., "Real Time Quantitative 3-D Imaging of Diffusion Flame Species," Proceedings of 4th Microgravity Combustion Workshop, NASA CP-10194, pp. 281-286, 1997.

6. Silver, J.A., "Quantitative Measurement of Oxygen in Microgravity Combustion," Proceedings of 4th Microgravity Combustion Workshop, NASA CP-10194, pp. 293-298, 1997.

7. Silver, J.A., Wood, W.R., Chen, S-J, Dahm, W.J.A., and Piltch, N., "Quantitative Species Measurements in Microgravity Combustion Flames," Sixth International Microgravity Combustion Workshop, NASA/CP-2001210826, pp. 61-64.

8. Silver, J.A., Kane, D.J., and Greenberg, P.S., "Quantitative Species Measurements in Microgravity Flames with Near-IR Diode Lasers," Applied Optics, vol. 34, pp. 2787-2801, 1995.

9. VanDerWege, B.A., O'Brien, C.J., and Hochgreb, S., "Application of Shear Plate Interferometry to Jet Diffusion Flame Temperature Measurements," Proceedings of the 4th Microgravity Combustion Workshop, NASA CP-10194, pp. 141-146, 1997.

10. Lim, J., Sivathanu, Y., and Feikema, D.A., "Fan Beam Emission Tomography for Estimating Scalar Properties in Laminar Flames," NASA/TM-2003-212302. 
11. Greenberg, P.S., Klimek, R.B., and Buchele, D.R., "Quantitative Rainbow Schlieren Deflectometry," Applied Optics, vol. 34, pp. 3810-3822, 1995.

12. Schardin, H., "Schlieren methods and their applications," NASA Rep. TT-F-12731 (NASA, Greenbelt, MD, 1970), Ergeb. Exakten Naturwiss, 20, 303, 1942.

13. Merzkirch, W., Flow Visualization, Academic, New York, pp. 71-102, 1974.

14. Settles, G.S., Schlieren and Shadowgraph Techniques: Visualizing Phenomena in Transparent Media, Springer-Verlag, Berlin, Heidelberg, NY, 2001.

15. Buchele, D.R. and Griffin, D.W., "Compact Color Schlieren Optical System," Applied Optics 32, pp. 4218-4222, 1995.

16. Howes, W.L., "Rainbow Schlieren and its Applications," Applied Optics, vol. 23, pp. 2449-2460, 1984.

17. Weinberg, F.J., Optics of Flames, pp. 23-37, Butterworth Publishers, 1963.

18. Tse, S.D., Zhu, D.L., He, L., Sung, C.J., and Law, C.K., "Microgravity burner-generated spherical diffusion flames: experiment and computation," Combustion and Flame, 125, pp. 1265-1278, 2001.
19. Handbook of Chemistry and Physics, 62nd ed., R.C. and M.J. Astle Editors, E-381, 1982.

20. Rubinstein, R. and Greenberg, P.S., "Rapid Inversion of Angular Deflection Data for Certain Axisymmetric Refractive-Index Distributions," Applied Optics, vol. 33, no. 7, 1994.

21. Al-Ammar, K.N., "Scalar Measurements and Analysis of Hydrogen Gas-Jet Diffusion Flames in Normal and Microgravity," Ph.D. Thesis, University of Oklahoma, 1998.

22. Al-Ammar, K., Agrawal. A.K., Golhalli, S.R., and Griffin, D.W. Experiments in Fluids, vol. 25, pp. 89-95, 1998.

23. Santoro, R.J., Semerjian, H.G., and Dobbins, R.A., "Soot Particle Measurements in Diffusion Flames," Combustion and Flame, 51: 203-218, 1983.

24. Kean, L., "Coefficients for Axisymmetric Schlieren Evaluations," ASD Technical Note 61-56, USAF Publication, Unclassified, 1961.

25. Gardiner, Jr., W.C., Hidaka, Y., and Tanzawa, T., "Refractivity of Combustion Gases," Combustion and Flame, 40, pp. 213-219, 1981. 
Public reporting burden for this collection of information is estimated to average 1 hour per response, including the time for reviewing instructions, searching existing data sources, gathering and maintaining the data needed, and completing and reviewing the collection of information. Send comments regarding this burden estimate or any other aspect of this collection of information, including suggestions for reducing this burden, to Washington Headquarters Services, Directorate for Information Operations and Reports, 1215 Jefferson Davis Highway, Suite 1204, Arlington, VA 22202-4302, and to the Office of Management and Budget, Paperwork Reduction Project (0704-0188), Washington, DC 20503.

\begin{tabular}{|l|l|l}
\hline 1. AGENCY USE ONLY (Leave blank) & $\begin{array}{c}\text { 2. REPORT DATE } \\
\text { June } 2004\end{array}$ & $\begin{array}{c}\text { 3. REPORT TYPE AND DATES COVERED } \\
\text { Technical Memorandum }\end{array}$ \\
\hline
\end{tabular}

4. TITLE AND SUBTITLE

5. FUNDING NUMBERS

Quantitative Rainbow Schlieren Deflectometry as a Temperature Diagnostic for

Spherical Flames

6. AUTHOR(S)

Douglas A. Feikema

7. PERFORMING ORGANIZATION NAME(S) AND ADDRESS(ES)

National Aeronautics and Space Administration

John H. Glenn Research Center at Lewis Field

Cleveland, Ohio 44135-3191

WBS-22-101-42-02

9. SPONSORING/MONITORING AGENCY NAME(S) AND ADDRESS(ES)

National Aeronautics and Space Administration

Washington, DC 20546-0001

8. PERFORMING ORGANIZATION REPORT NUMBER

E-14351-1

10. SPONSORING/MONITORING AGENCY REPORT NUMBER

NASA TM-2004-212955

AIAA-2004-0958

\section{SUPPLEMENTARY NOTES}

Prepared for the 42nd Aerospace Sciences Meeting and Exhibit sponsored by the American Institute of Aeronautics and Astronautics, Reno, Nevada, January 5-8, 2004. Responsible person, Douglas A. Feikema, organization code 6711, 216-433-5707.

12a. DISTRIBUTION/AVAILABILITY STATEMENT 12b. DISTRIBUTION CODE

Unclassified - Unlimited

Subject Categories: 25, 35, 74, and 29

Distribution: Nonstandard

Available electronically at http://gltrs.grc.nasa.gov

This publication is available from the NASA Center for AeroSpace Information, 301-621-0390.

\section{ABSTRACT (Maximum 200 words)}

Numerical analysis and experimental results are presented to define a method for quantitatively measuring the temperature distribution of a spherical diffusion flame using Rainbow Schlieren Deflectometry in microgravity. First, a numerical analysis is completed to show the method can suitably determine temperature in the presence of spatially varying species composition. Also, a numerical forward-backward inversion calculation is presented to illustrate the types of calculations and deflections to be encountered. Lastly, a normal gravity demonstration of temperature measurement in an axisymmetric laminar, diffusion flame using Rainbow Schlieren deflectometry is presented. The method employed in this paper illustrates the necessary steps for the preliminary design of a Schlieren system. The largest deflections for the normal gravity flame considered in this paper are $7.4 \times 10^{-4}$ radians which can be accurately measured with 2 meter focal length collimating and decollimating optics. The experimental uncertainty of deflection is less than $5 \times 10^{-5}$ radians.

\begin{tabular}{|c|c|c|}
\hline \multicolumn{3}{|c|}{$\begin{array}{l}\text { Microgravity combustion science; Numerical calculations } \\
\text { Measurements }\end{array}$} \\
\hline $\begin{array}{l}\text { 17. SECURITY CLASSIFICATION } \\
\text { OF REPORT }\end{array}$ & $\begin{array}{l}\text { 18. SECURITY CLASSIFICATION } \\
\text { OF THIS PAGE }\end{array}$ & $\begin{array}{l}\text { 19. SECURITY CLASSIFICATION } \\
\text { OF ABSTRACT }\end{array}$ \\
\hline Unclassified & Unclassified & Unclassified \\
\hline
\end{tabular}



